
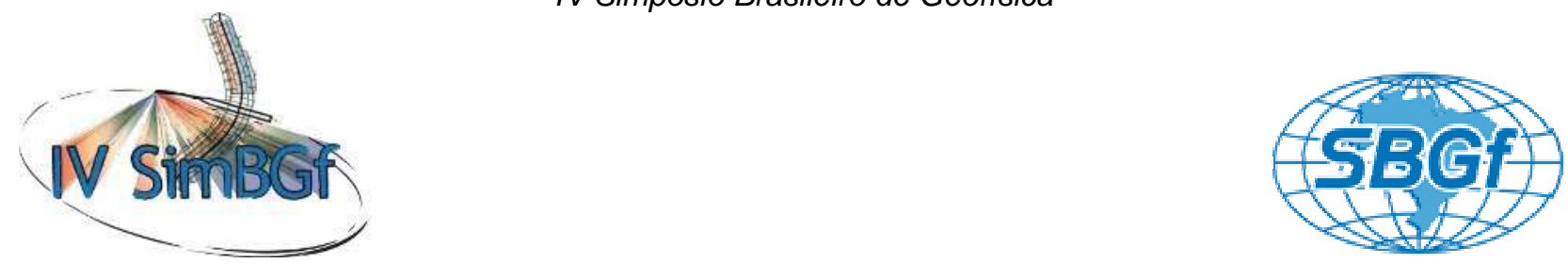

\title{
Interpretação e Análise Sismoestratigráfica da Sequência Pós-Miocênica na Bacia de Campos
}

Elionardo Moraes Pintas, Curso de Graduação em Geofísica, Universidade Federal Fluminense, Brasil.

Eliane da Costa Alves, Departamento de Geologia, Universidade Federal Fluminense, Brasil.

Copyright 2010, SBGf - Sociedade Brasileira de Geofísica

Este texto foi preparado para a apresentação no IV Simpósio Brasileiro de Geofísica, Brasília, 14 a 17 de novembro de 2010. Seu conteúdo foi revisado pelo Comitê Técnico do IV SimBGf, mas não necessariamente representa a opinião da SBGf ou associados. É proibida a reprodução total ou parcial deste material para propósitos comerciais sem prévia autorização da SBG.

\section{Resumo}

Este trabalho tem como objetivo utilizar as técnicas de interpretação sismoestratigráfica, com base em dados sísmicos de reflexão $2 \mathrm{D}$, na borda de plataforma da bacia de Campos para descrever e identificar as grandes descontinuidades, os padrões de sedimentação, as sismofácies e principalmente os Tratos de Sistema da seção pós-miocênica na bacia. Esta identificação se faz necessária para uma posterior análise paleogeográfica e tem o intuito de identificar possíveis plays para a exploração de hidrocarbonetos.

\section{Introdução}

Bacia de Campos é uma bacia típica de margem continental divergente, com uma história evolutiva semelhante às das demais bacias da costa leste brasileira: pode ser dividida geralmente em três grandes megassequências com características tectonosedimentares distintas, que resultaram do processo de rifteamento do Gondwana e de abertura do oceano Atlântico Sul:

Sequência Continental (Rifte), englobando os basaltos e parte dos sedimentos continentais da formação Lagoa Feia, afetados pela tectônica rifte;

Sequência Transicional (Evaporítica), caracterizada pela deposição dos evaporitos e por relativa quiescência tectônica e;

Megasseqüência Marinha (Margem Passiva), caracterizada pela deposição marinha franca (carbonática no início e predominantemente siliciclástica nas fases finais), afetada por intensa tectônica adiastrófica (Ponte \& Asmus, 1976; Dias et al., 1990; Cainelli \&Mohriak, 1999).

A bacia de Campos destaca-se por algumas características de sua evolução tectono-sedimentar que resultou na mais importante bacia petrolífera do Brasil. Portanto esta é uma região que, embora tenha gerado grande interesse, por conta da riqueza em hidrocarbonetos ali existente, poucas informações se encontram disponíveis na literatura científica sobre importantes questões relacionadas à Arquitetura sedimentar dos estratos depositados. Assim, algumas questões importantes sobre a arquitetura sedimentar rasa da bacia permanecem ainda em aberto.

Nesse contexto, este trabalho está inserido dentro do projeto de pesquisa de iniciação científica em geologia e geofísica baseada em dados geofísicos para exploração de hidrocarbonetos. Para a realização deste projeto de pesquisa serão utilizados dados sísmicos 2-D pós stack, adquiridos junto ao Banco de Dados de Exploração e Produção (BDEP-ANP). E torna-se relevante por toda a importância tanto para o meio acadêmico quanto para a geofísica exploratória, podendo esclarecer e contribuir para uma maior compreensão da seção pós-sal, que ultimamente tem gerado novas descobertas, principalmente na plataforma continental.

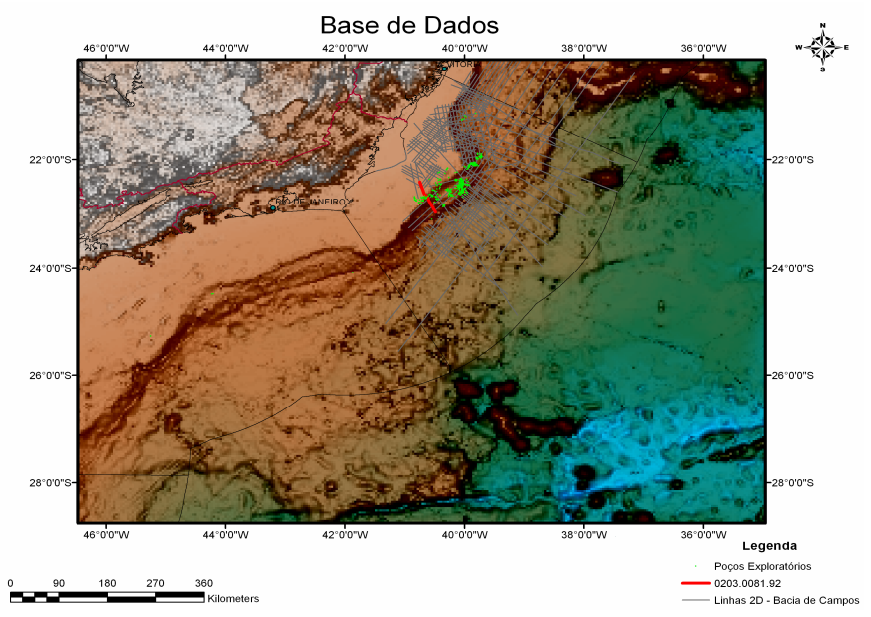

Figura 1 - Mapa Topográfico da margem sudeste brasileira e localização da linha Sísmica 0203-0081 interpretada em vermelho (dados topográficos de Smith, W. H. F., and D. T. Sandwel, 1997).

\section{Metodologia/ Problema Investigado}

A interpretação desta linha atendeu aos métodos sismoestratigráficos (Mitchum \& Vaill, 1977; Mougenot et al., 1983; Posamentier e Vail, 1988; Posamentier et al., 1992). A partir da análise dos perfis de sísmica de reflexão foi possível inicialmente identificar e mapear as grandes megassequências da bacia. Destas foi dada uma ênfase na megassequência marinha (margem passiva), principalmente pós-miocênica, onde se evidenciou as grandes descontinuidades (como a da 
base do Oligoceno), as sismofácies, os tratos de sistema e os padrões de sedimentação (caótico no embasamento e no sal; plano-paralelas e contínuas na seção marinha; e sigmoidal nas progradações) (Figura 4).

Na figura 2 vê-se um modelo do conceito dos Tratos de Sistema, tal modelo mostra quatro tratos de sistema associados às curvas eustáticas, suas superfícies e principais descontinuidades. Este modelo serve como análogo para aplicação geral, porém devem ser modificados e ajustados para levar em consideração os fatores locais de uma determinada bacia, ou seja, notar que pode haver erosões associadas, logo algumas fases podem ter sido subtraídas do registro sedimentar.

Tais fatores foram encontrados em dados bibliográficos (Pedro, 2005; Oreiro, 2006) e serviram como base para a interpretação dos principais horizontes, uma vez que muitas datações e marcos estratigráficos já foram instituídos. É evidente que todo um pressuposto teórico foi necessário para dar credibilidade ao modelo interpretativo mostrado na figura 4.

Primeiramente foi identificada a grande inundação do oligoceno e uma descontinuidade miocênica que culminou com a marcação de uma seção condensada referente a uma superfície de inundação máxima. Posteriormente foram identificados os off-lap breaks que marcam as paleoquebras de plataforma (paleopraias). Com estas interpretações e correlações bibliográficas pode-se tentar entender a interação sedimentação, nível relativo do mar e subsidência. A partir destes parâmetros podem-se sugerir os principais limites entre progradações e retrogradações. Logo ao final foram analisados os Tratos de Sistemas.

Para a realização deste trabalho foram interpretadas quatro linhas sísmicas, todas na altura do cabo de São Tomé, na borda de plataforma da bacia de Campos (Figura 1).

\section{Resultados}

A linha sísmica de orientação NW-SE localizada na figura 1 mostra a sedimentação na margem de plataforma e talude continental (marcada em vermelho). Observa-se um sistema distensivo caracterizando a movimentação das sequências sedimentares sobre um nível de sal alóctone, caracterizado por almofadas, diápiros e estruturas conhecidas como cascos de tartaruga (Figura 3). Nessa linha sísmica é possível observar a presença de inúmeras falhas relacionadas à movimentação desta camada salinífera, a maoiria dessas falhas atingem grande parte das camadas sobrepostas.

Acima do refletor marcado como sendo oligocênico (Pedro, 2005) identificam-se refletores plano-paralelos com terminações em onlap que sugerem uma transgressão marinha associado a um trato de sistema transgressivo. Esta grande subida do nível do mar oligocênica é amplamente divulgada e conhecida mundialmente e é utilizada como um marco estratigráfico muito importante, este refletor serviu como uma base para interpretação e realização do presente trabalho. Ainda nesta sequência de

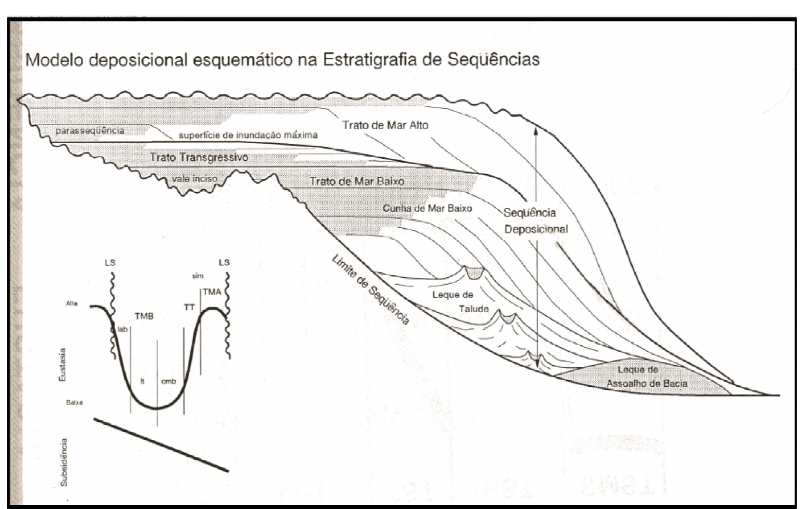

Figura 2 - Modelo teórico contendo as curvas de Eustasia, de subsidência e os Tratos de Sistema. (Retirado de Jobel Moreira, 2000).

característica transgressiva pode-se identificar uma superfície de ravinamento, que também pode sugerir uma evidência de subida do nível relativo do mar e retrogradação de todo sistema praial .

$\mathrm{Na}$ altura de 1,8 ms TWTT (tempo duplo de trânsito) no extremo SE da linha são observados escorregamentos de massa, com uma escarpa associada e refletores bem caóticos na altura do fundo marinho.

Mais acima foi definido o horizonte miocênico, logo acima deste horizonte foi identificada uma superfície de inundação máxima, evidenciada pela marcação de seção condensada (em marrom), sobre esta superfície há o primeiro Trato de Sistema de Mar Alto (em verde), o que Falta bibliografia para todas essas afirmações são as sequências progradantes sigmoidais apoiadas por caracterísitacas de offlap breaks mostrando que pode sugerir a uma agradação associada. Nesta sequência também é observado a presença de imensas estruturas em quilha, com onlaps para ambos os lados dentro desta estrutura. Tal morfologia pode ser interpretada como sendo um paleocanal preenchido. Morfologias estas foram diversas vezes identificadas tanto nesta seção sísmica quanto nas outras três que foram interpretadas.

O próximo Trato de Sistema evidenciado foi o de Mar Baixo, que veio acompanhado de uma superfície de erosão do tipo dois, sem exposição subaérea. Tal afirmação é apoiada pela relativa baixa do offlap break, pela presença de discordância erosiva e também por uma feição bem à NE da linha na altura dos $1,9 \mathrm{~ms}$ TWTT: os leques de mar baixo ou leques de assoalho de bacia. O nível relativo do mar elevou-se novamente e formou uma morfologia cognata com o primeiro Trato de Sistema de Mar Alto, o interessante é notar uma erosão bem pronunciada na base deste, que provavelmente deve-se à nova transgressão marinha associada.

A mais recente arquitetura sedimentar identificada seria um Trato de Sistema de Margem de Plataforma, assim descrito por conter offlap breaks quase que verticalizados, superfícies plano paralelas e feições de 
escorregamentos de massa bastante comuns na borda de plataforma.

\section{Discussão e Conclusões}

O método de interpretação sísmica mostrou-se mais uma vez muito eficiente, sendo capaz de identificar as sequências deposicionais, as sismofacies e finalmente estes serviram para analisar os Tratos de Sistemas que são de suma importância do ponto de vista petrolífero, pois são estas sequências podem servir de análogo para caracterizar um prospecto (plays), contendo análogos para possíveis rochas reservatório (por exemplo, as areias transgressivas que são bem selecionadas e por assim serem podem conter porosidade e permeabilidades atrativas), selante (os folhelhos presentes na seção condensada, ou os finos que são depositados na porção mais distal de uma progradação) e geradora (as seções condensadas são conhecidas por conterem grandes concentrações de matéria orgânica). Portanto o correto estudo desses Tratos é uma ferramenta poderosa não somente na exploração de hidrocarbonetos, mas também para caracterização paleogeográfica de uma área.

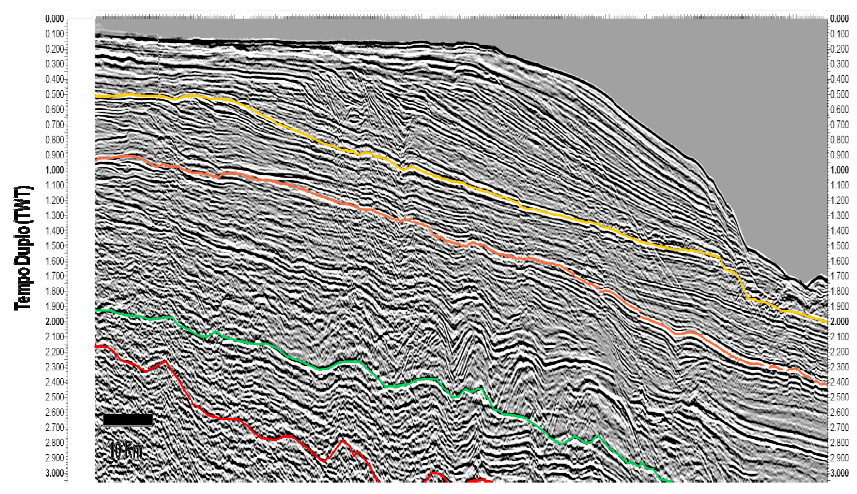

Figura 3 - Linha sísmica 0203-0081 não interpretada. plataforma ao talude superior. Lagemar. Niterói,RJ,Brasil,UFF.

Oreiro, S. G. (2006). Magmatismo e sedimentação em uma área na Plataforma Continental de Cabo Frio, Rio de Janeiro, Brasil, no intervalo Cretáceo Superior - Terciário. B. Geoci. Petrobras. Rio de Janeiro. 14: 95 - 112.

Pedro, A. J. (2005). Utilização da Sismoestratigrafia no Estudo da Atuação do Alto de Cabo Frio na Sedimentação na Porção Sul da Bacia de Campos. Lagemar. Niterói, RJ, Brasil, UFF. Masters: 97.

Severiano Ribeiro, H.J.P (2001). Estratigrafia de Sequências Fundamentos e Aplicações, Editora UNISINOS, São Leopoldo, 428p

\section{Agradecimentos}

Agradeço ao Pibic/CNPq pela bolsa de apoio, ao Lagemar pelos dados, à minha orientadora Eliane Alves pelos conselhos, ao professor Cristian Gorini pelo curso de estratigrafia de sequências e a todos que contribuíram de alguma forma para este trabalho.

\section{Referências}

Almeida, F. F. M., Carneiro, C. R. (1998). Origem e Evolução da Serra do Mar. Revista Brasileira de Geociências. 28: 135 - 150.

Kinkela, N'Landu. (2005). Interpretação Sismoestratigráfica, da área sul da Bacia de Campos, da 


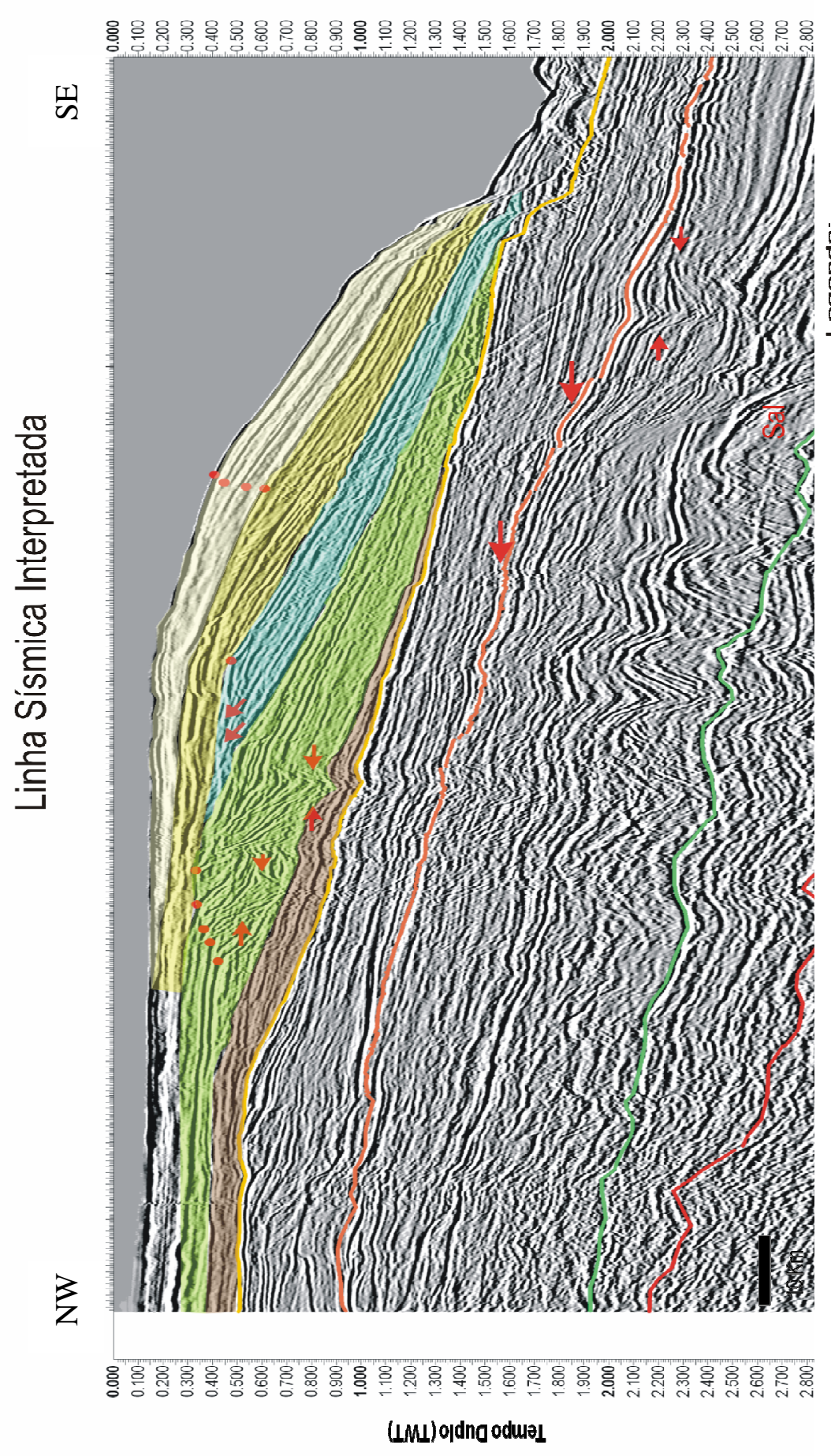

용 용

空

일

\% $\sum_{0}^{\infty}$

$\stackrel{0}{\stackrel{0}{*}} \frac{0}{\frac{1}{4}}$

홀 $\frac{\bar{\pi}}{\Sigma}$

$\frac{1}{2}$

$\frac{10}{8} \div 8$

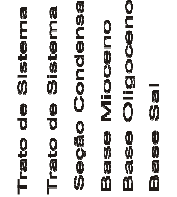

$\frac{0}{0} \frac{0}{0}$

응 용

定的

용 \&

인용

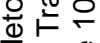

힌 $11 \frac{8}{5}$

잉 전

है

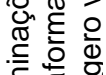

产要离

is

을 $\frac{8}{8}$

존 윻

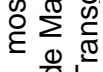

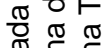

蛋

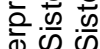

$\stackrel{\Phi}{=} \stackrel{0}{0}$

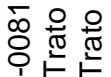

Оิ่

¿

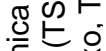

क्ष

宁

글 응

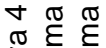

竞离

婇的

(เML) 이ng oduə] 